\title{
Intervención en un Ministerio
}

\author{
Horacio Foladori ${ }^{1}$ \\ Livia Sepúlveda
}

\begin{abstract}
Resumen
El trabajo que se presenta constituye una intervención de análisis institucional realizada en una oficina de un ministerio. Se analiza la demanda, la realización del contrato, la propuesta metodológica y técnica y con minuciosidad el devenir del trabajo grupal según transita por diversos conflictos que atañen a la burocracia. Por último, se señalan algunas conclusiones y recomendaciones a las autoridades.
\end{abstract}

Palabras claves: Conflicto, análisis institucional, determinaciones, grupo operativo

\begin{abstract}
This paper shows an intervention based on the institutional analysis theory, done in a section of a Secretary. The report includes the analysis of the demand, the contract, the methodology, the techniques used and de movement of the group work through the different conflicts related to burocracy, that arrows in its way. At last, some conclusions and recommendations to the authorities are indicated.
\end{abstract}

Key words. conflict, institutional analysis, determinations, operative group

\section{Introducción}

El caso que aquí se detalla y analiza forma parte, como se podrá apreciar, de una situación límite ya que pone en tala de juicio a los mismos modelos de intervención. La referencia a los marcos teóricos no puede soslayarse cuando a veces los esquematismos atrapan al especialista en una escucha parcializada de lo que acontece en la institución. Muchas veces se "bajan" modelos de manera mecánica, porque pueden ser los únicos que se conocen, sin preguntarse muchas veces acerca de las complicidades que el especialista sostiene con la institución. El análisis de la implicación - a nuestro juicio - resulta imprescindible para ampliar (aunque más no sea levemente) la apertura de "las anteojeras" que todo sujeto tiene en una situación determinada, en tanto es atravesado por innumerables instituciones que lo constituyen.

De ahi que nuestra opción no es por un "desarrollo organizacional", en el sentido de que previamente se determina que la organización debe ser desarrollada, lo cual supone una alianza tácita con el staff cliente en tal sentido. Preferimos situarnos en la línea del análisis institucional que postula metodológicamente, la situación de análisis como de búsqueda e identificación de los elementos que componen la institución, y de institucional por que hay que dar cuenta de las luchas de poder al interior de las instituciones (que incluye lo organizacional, pero también lo ideológico, así como lo libidinal). Creemos que en la esfera de lo público es más acuciante la necesidad de esta diferencia ya que hay un interés colectivo más allá de un

${ }^{1}$ Psicólogo, psicoanalista. Doctorado en Filosofia. Docente del Depto. de Psicología de la U. de Chile. Director de la Escuela de Psicología Grupal y Análisis Institucional. e-mail:foladoriactcreuna.cl 
eficientismo inmediato...; el beneficiario no es el ministro del ramo sino la totalidad de la población incluyendo a los funcionarios mismos.

\section{Origen de la Demanda. ${ }^{(1)}$}

La demanda de intervención en la Oficina de Partes se origina en una serie de hechos acontecidos en la misma y que oficiaron como factor desencadenante de la consulta.

a. El hecho más significativo lo constituyó la detección de un caso de tuberculosis en la Oficinay que naturalmente generó alarma en el Ministerio, por cuanto la situación amenazaba no solamente al resto de los funcionarios de la Oficina sino también a otros sectores . La situación fue abordada de manera inmediata por la enfermera del Ministerio que solicitó apoyo a otras reparticiones del Estado. En todo caso, este aspecto mostró varias realidades, a saber:

b. El grado de hacinamiento en que esta Oficina se encontraba y la necesidad de disponer de remodelaciones edilicias urgentes en varias secciones, lo que se comenzó a realizar en su momento y se mantiene hasta el presente.

c. El altísimo porcentaje de licencias médicas solicitadas por funcionarios de esta Oficina, la presencia de enfermedades psicosomáticas de largo arraigo, intervenciones médicas, etc.

d. La presencia de un indice significativo de depresión entre el grupo de funcionarios que también incidía en la necesidad de licencias médicas de mayor duración.

e. La edad promedio de los funcionarios de la oficina que a ojos de las autoridades administrativas es elevado.
Estos aspectos habian motivado la intervención de un sociólogo quien realizó un primer taller-diagnóstico sobre el clima laboral en la Sección de archivos y partes, y en donde se detectó además una serie de problemas interpersonales variados entre los funcionarios, asi como dificultades en las relaciones con el Jefe de la Oficina. Este preámbulo hizo conciencia sobre la necesidad de una consulta de mayor envergadura a los efectos de generar una intervención que "ayudara a las personas a comprender algo de lo que alli acontecia" y que sirviera también para estudiar algunas de las determinaciones de las relaciones laborales particulares de la Oficina.

Se solicitó así un proyecto al equipo consultor (2) el que fue presentado en abril de 1998.

\section{Contratode Trabajo}

En junio, el equipo consultor es solicitado nuevamente para iniciar la intervención. El proyecto presentado y que fue aceptado en su totalidad, establecia algunas condiciones, a saber:

a. Que durante la intervención - que se fijaba en 20 sesiones, vale decir aproximadamente durante 5 meses - no se realizaran intervenciones de otras consultoras. El motivo de esta condición apuntaba a rescatar la importancia y significación de la intervención para el Ministerio y facilitar la concentración emocional de los participantes sobre una única actividad.

b. La necesidad de que todos los funcionaros que participaran lo hicieran voluntariamente. Este requisito se basaba en la necesidad de rescatar el deseo propio de cada quién, ya que en este terreno nadie puede ser "esclarecido", si no desea hacerlo, a diferencia de lo que sucede en un curso de capa-

\footnotetext{
(1) Parael investigador socio-institucional, la demandase convierte en un hugar de condensaciones (personales, grupales, sociales, politicas, institucionales, etc.) de un sinnúmero de requerimientos de los más diversos sectores y que obedecen a discímiles intereses. Alli, portanto, es donde el proceso se inicia, por lo que su análisis se constituye en el primermovimiento que el grupo realizadesencadenando asu vez los pasos sucesivos.

(2) El equipo consultor se constituyó con psicólogos con formación en trabajo grupal dinámico y en análisis institucional. El modelo implementado en este caso se distancia de lo que puede ser un curso de capacitación corriente, en el sentido de generar un dispositivo de intervención que permita develar las determinaciones profundas que afectan al grupo a través de una metodología de escuchay análisis, en vez de la entrega de consejos o conocimientos. El equipo consultor sostiene asila tesis de que en la medida en que el grupo participay analizasus situaciones, se esclarece y descubre las conecciones entre su sufrimento (psiquico e institucional) y sus padecimientos (fisicos uorgánicos).
} 
citación. La institución había aportado un escrito en el cual los funcionarios se comprometían voluntariamente a asistir.

Como se verá, esta institución vertical hizo que no haya elección posible: los funcionarios no se animan a expresar su discrepancia y decir NO, se escabullen sin enfrentar la situación y actúan el descontento institucional saboteando de diversos modos.

Lo significativo es que la institución no cumplió ninguna de estas dos condiciones.

Durante toda el trabajo sostuvo intervenciones con otras consultoras, asi como los funcionarios fueron "comisionados" a diversos cursos que los extraía del campo de intervención. Con esto, el propio Ministerio implícitamente comunicaba su desconfianza sobre la intervención, así como que su compromiso era algo meramente formal. Esto fue señalado por el equipo consultor en oficio de septiembre de 1998.

A su vez, también en su momento presionó a los funcionarios para que concurriesen a las reuniones.

El modelo de intervención consistió en organizar dos grupos paralelos (ya que se habian inscrito cerca de 20 funcionarios) en horarios complementarios a los efectos de que las diversas dependencias no quedaran sin personaly pudieran continuar trabajando.

Se instituyó un espacio " para hablar" de todo lo que tuviese que ver con el desarrollo del trabajo. La técnica consistía en producir un discurso que era permanentemente precisado, interrogado y esclarecido por el equipo consultor, con un momento de devolución en que el observador re-leía aquellos dichos del discurso grupal que configuraban verdaderos nudos conflictivos, al expresar no solamente situaciones emocionales significativas sino también tomas de conciencia que marcaban el proceso del grupo (3).

En suma, se trataba de construír un espacio de reflexión y análisis de los problemas en el entendi- do de que tienen que ser los propios funcionarios siasílo desean - los que pueden esclarecerse acerca de las motivaciones de lo que les acontece. Se señaló que no se iban a dar consejos, recomendaciones, sugerencias, etc. ,ya que los problemas nunca pueden ser solucionados desde "afuera" ( tratar a los funcionarios como sujetos dependientes refuerza el paternalismo que la propia institución genera y cuyo efecto, en parte, es visualizado a través de una amplia gama de sintomas como ser la apatía, la depresión, etc.).

El trabajo de intervención comenzó en julio de 1998 y se desarrolló sin interrupciones hasta noviembre como estaba previsto.

Inicialmente, se comenzó a trabajar en un local que fue sustituído por otro, en el que se funcionó de manera definitiva.

\section{Caracteristicas del grupode Funcionarios}

\subsection{Expectativas}

Las primeras reuniones dieron cuenta de las expectativas de los funcionarios en cuestión.

a. Se expresó que "creían que se trataría de un sólo taller", vale decir, la institución generó un malentendido, tal vez para obtener la anuencia de los funcionarios a participar. Fue necesario entonces comenzar a mostrar que los problemas tenian larga data y era ilusorio suponer que en una sesión aislada se podían obtener esclarecimientos sobre situaciones tan complejas.

b. La actitud de los funcionarios fue - como es habitual según la mecánica de los "cursos" - la de esperar que los expertos les dijeran qué tenían que hacer y por qué les sucedía lo que acontecía.

Por tanto, se hizo también necesario mostrar que la ansiada "mejoría" era un trabajo que debería ser hecho por todos, que era un "producto" al cual se 
podria arribar pero que había que trabajar para ello. No fue poco el desconcierto.

c. Inicialmente se atribuyó a "problemas familiares" la presencia de tantos problemas en la Oficina. Ello significaba plantear la cuestión en términos de "no nos metamos con la vida privada de nadie", lo que constituia una resistencia férrea al trabajo grupal que teniamos que hacer: abrir los problemas, animarse a mirarlos y esclarecerlos. Naturalmente, la intervención era sentida como amenazante ya que requeria de un grado de confianza y de compromiso emocional con el trabajo de análisis. Por ello, la insistencia en solicitar recomendaciones que siempre permanecen como "exteriores" al sujeto y le permite jugar con la ilusión de que él elige si las va a aplicar o no.

d. Por otro lado, el equipo consultor se convertia en un intermediario entre los funcionarios de la Oficina y las autoridades administativas, por lo que - en el imaginario del grupo - podria negociarse a través del equipo mejoras laborales (salarios, ascensos, vacaciones, beneficios diversos, etc.), con lo que algunas sesiones se convirtieron en "mesa de negociaciones" de las condiciones de trabajo. Con ello, los funcionarios al contar con "abogados defensores" evitaban tener que asumir ellos mismos los reclamos que deseaban hacer a las autoridades y jugársela por sus ideas y proyectos.

e. También estuvo presente desde el inicio la idea de que por estar el equipo interventor formado por psicólogos, las reuniones se transformarian en una suerte de terapia de grupo; $y$ más aún por cuanto el indice de enfermedades psicosomáticas y depresión figuraban entre los motivos de la convocatoria. Pero se trataba de una "terapia de grupo" que no era solicitada personalmente como tal, porque ello significaba asumirse como enfermo: jugar a la terapia de grupo entonces, lo que implicaba la propia negación del intento.

\subsection{Desarrollosintético del Proceso}

Cada uno de los subgrupos adquirió desde el inicio características propias. Sin perjuicio de ello, el proceso que siguieron fue similar. Transitaron por diversas etapas y fue interesante detectar de qué manera el conflicto central del grupo fue variando a lo largo del proceso. En este sentido sostenemos que lo que llamamos el conflicto central, es aquel lugar en el que aparece la mayor concentración de fuerzas opuestas. Pero las fuerzas son móviles y según se esclarecen distintas escenas, es decir, de ser vividas como situaciones antagónicas, pasan a ser situaciones complementarias; se disuelve el conflicto que aparece nuevamente polarizado en otro par de situaciones.

Se puede mostrar que el conflicto nació centrado en situaciones personales e interpersonales, al poco tiempo se polarizó en la figura de la jefatura de la Oficina, más tarde adquirió la tonalidad de los problemas internos a cada subsección, posteriormente se hizo presente como conflicto con la institución total:el Ministerio. Mas tarde se polarizó en un férreo cuestionamiento al gremio para adquirir por último la tonalidad de los conflictos intrafamiliares. Cada uno de estos momentos deberá ser mostrado y explicado ya que conlleva la respuesta al interrogante general que convoca la intervención, vale decir, ¿cuáles son las determinaciones del estrés laboral? El grupo contesta TODAS ELLAS, lo cual no significa que todas operen con el mismo peso, ni tampoco que lo hagan de igual modo en todos y cada uno de los funcionarios de la Oficina. De hecho, cada participante se vió afectado de distinta manera por el proceso global.

\section{Desarrollo de los Momentos del Conflicto}

A los efectos de visualizar claramente el desarrollo del conflicto anteriormente descrito, se detallarán los diversos momentos con las enunciaciones que dan cuenta de su identificación, a saber: 


\subsection{Momento de los conflictos personales.}

La primera respuesta del grupo de funcionarios tiene que ver con cómo ellos justifican lo que les sucede en el Ministerio. Parten de la base de que muchos de los funcionarios concurren al trabajo con una gran carga emocional producto de situaciones familiares, es decir, los conflictos personales los indisponen para el trabajo en común ya que se sienten deprimidos, enojados, alegres, etc. según como vengan desde sus propias casas. Se juega aquí una cierta manera de pensar los problemas ya que sobre todo la impotencia ante los conflictos hogareños y la imposibilidad de estar alli (para solucionarlos, ya que tienen que ir a trabajar) hace que lo hagan con disgusto. Así, atribuyen a una determinada "naturaleza humana" lo que les sucede en el trabajo: son desleales, tienen problemas de caracter, contestan de mala manera, tienen falta de educación, tienen familiares enfermos graves, sufren de desconfianza entre ellos, etc. etc.

Dicho argumento no toma en cuenta que - triste es decirlo - en realidad hay un tiempo mayor que pasan en el empleo, comparativamente con aquel destinado al hogar y que la explicación podría ser casualmente la contraria, vale decir, que se llevan los conflictos del trabajo a la casa: si están más de 8 horas en el trabajo y deben viajar en muchos caso no menos de dos o tres más, llegan a la casa para cenar y acostarse, por lo que el tiempo en la casa es exiguo.

\section{2. Momento delos conflictos con lajefatura.}

Superado el momento inicial y señalada la contradicción en el argumento, el grupo se centra ahora en su situación interna. En tal sentido, se unen contra lajefatura a quien acusan de todos los males que les toca vivir. Veamos en detalle:

a. Despreocupación por parte de la jefatura (no son tomados en cuenta, no son alentados, no se compromete ni se la juega por sus empleados) .

El sentir generalizado es de que existe una gran distancia entre la jefatura y el grupo de funcionarios. Rara vez son tomados en cuenta o consulta- dos en sus opiniones. Menos aún son alentados en su trabajo. Plantean airadamente que un jefe debe jugársela por sus funcionarios cosa que en este caso no ocurre.

b. Envidias de los privilegios (los regalones, chupamedias).

A su vez el jefe no trata a todos por igual sino que tiene a "sus regalones" $y$ "sus chupamedias" lo cual hace que los niveles de exigencia sean diferentes para cada quién. Están aquellos que "se saben colocar" con el jefe y otros que sencillamente se mantienen en la perisferia.

c. Arbitrariedad en la distribución de las horas extraordinarias, y en los contratos nuevos.

Otra queja muy significativa tiene que ver con la manera arbitraria en como la jefatura ejerce sus funciones. Si hay regalones hay algunos más beneficiados que otros de aquello que se produce como "reparto": no a todos les toca gozar del beneficio de hacer horas extras, si bien las licencias médicas numerosas producen necesidad de más trabajo. Mas significativo e hiriente para los funcionarios es ver que algunas nuevas contrataciones se realizan a salarios muy superiores a los que establece el escalafón o que hay funcionarios que son "ascendidos" varios grados en el momento de la contratación.

d. Inseguridad (El miedo a que si la jefatura también se ve amenazada desde instancias superiores, eso los dejaria sin protección)

"Todos somos esclavos".

Reconocen que el jefe también sufre lo suyo ya que es probable que esté muy presionado desde "arriba" para obtener a su vez calificaciones buenas. Esto hace que esté permanentemente cuidándose para "no perder su pega". Ello repercute generando en los funcionarios la sensación de desamparo. Así, en el fondo, el grupo necesita cautelar la figura de la jefatura.

e. Se monopoliza la información.

El jefe cuenta con abundante información que no da a conocer a los funcionarios, información que puede ser imprescindible para realizar mejor el trabajo. Así como resulta "apretado" con la distribu- 
ción de horas , también lo hace con el manejo de la información.

f. Los jefes a su vez tienen la posibilidad de elegir los mejores "cursos "de capacitación, que son aquellos con los que se puede viajar al extranjero. En ese sentido losjefes aparecen como siendo muy envidiados por los funcionarios.

g. Abuso de poder por medio de la calificación (descalificación).

La queja más significativa la constituye el abuso que se hace, en opinión de los funcionarios, de las calificaciones. Las mismas tienen para ellos una destacadísima importanciaya que de alli dependen los ascensos y la posiblidad de ganar unos pocos pesos más. La califiación es el único elemento que los funcionarios pueden pretender controlar - vía un buen desempeño - ya que los otros elementos para obtener un mejor ingreso, depende de las "bondades de otros". Por ello, el problema de las calificaciones, los juicios que se emiten en las mismas y las repercusiones en cuanto a las comparaciones que resultan entre ellos, se convierte en el conflicto central con la jefatura.

Es interesante observar que la reacción de los funcionarios ante las calificaciones es diversa. Hay quienes prácticamente reconocen preocuparse mucho por la calificación y por la forma en que se aplican los juicios por parte de lajefatura; hay otros que pretenden "negar" su importancia, seguramente como una manera de neutralizar la propia sensación de impotencia que la arbitrariedad de la misma les produce. En todo caso, es un tema que no deja de poner al desnudo toda la situación laboral por lo que se convierte en un denunciante de la misma.

Esta queja sobre la jefatura adopta el modelo de una "situación familiar" un tanto conocida. Los funcionarios se quejan como si estuviesen ante un padre malo, arbitrario que no trata a todos los hijos por igual y que se reserva las mejores tareas y funciones. Pero a su vez, también plantean que el jefe "debe mandar" y coinciden en señalar que si la jefatura se manejara con "mano dura" hay cosas que no se tolerarian en la oficina. (Es evidente que la competencia y riña entre los funcionarios aumenta de manera manifiesta si el jefe es condecendiente). Resulta sorprendente este pedido, esta nueva queja que da cuenta de la enorme pasividad con que los funcionarios se enfrentan a la jefatura, prácticamente no tienen iniciativa y permanecen a la espera de que sea el jefe quien, a través de sus instrucciones los reconozcay les diga qué deben hacer. Este aspecto de la pasividad generalizada reviste singular relevancia ya que aparecerá de diversas manera a lo largo del taller y articulado con otros momentos. La pasividad es el efecto de la resignación ("tirar la toalla", "tirar la esponja", "no hay espiritu de cambio", "no se puede esperar retribución", "no calentarse la cabeza", "hacerse la lesa", etc.), que a su vez es, tal vez, el peor enemigo del cambio en la institución.

\subsection{Momento de los conflictos internos entre subsecciones.}

Cuando se les mostró que seguramente todos los males de la oficina no provenían solamente de la jefatura, se generó un tercer momento de desarrollo del conflicto que se pasó a centrar en las relaciones entre ellos mismos, entre las diversas subsecciones que conviven bajo la gran repartición de la Oficina de Partes.

\section{a Remodelaciones y locales.}

Si bien cuando comenzó el taller ya habian sido instalados en su nuevo local más cómodo, iluminado y ventilado, no todos los funcionarios pudieron gozar de inmediato de este beneficio. Hay secciones que tuvieron que mudarse transitoriamente a otros espacios o soportar durante bastante tiempo la operación de obreros trabajando en las mismas oficinas. Algunos arreglos y remodelaciones son vividas como necesarias; otras - como la entrada del Ministerio - a su juicio son prescindibles cuando tienen sueldos tan bajos. Además, se quejan de que sus opiniones sobre la funcionalidad de los espacios no es tomada en cuenta y que los arquitectos se preocupan más por lo bonito sin percatarse de las necesidades mínimas y sobre todo de la seguridad del local. 
b. Quién trabaja más, si los que atienden al público o los que están en escritorios.

Un larga discusión se dió entre los sectores que "atienden público" y otros que realizan un trabajo más apartado. Como si estuviesen en competencia permanente, discutieron siunos trabajaban mas que otros , los grados de tensión que se acumulaban en el trabajo ya sea por la rutina o por que se tenían que hacer cargo de las tensiones del público.

\section{c. Problema de los uniformes.}

Un desarrollo particular del punto anterior lo constituyó la discusión sobre el "beneficio" de los uniformes ya que se les había entregado a aquellos que atendian público. Este es un nuevo punto de rozamiento entre sectores ya que produce envidias muy agudas; sirve para etiquetar a aquellos favorecidos por la autoridad y a sentirse a su vez descalificado y despreciado por ésta.

\section{d. Estar a cargo de otros ( flojos).}

Así como discutieron sobre las diversas subsecciones también lo hicieron a partir de las relaciones entre ellos en los subequipos de trabajo. Les cuesta decirse las cosasy actúan sus enojos. Hay funcionarios que parecen tener más capacidad de trabajo que otros por lo que los "flojos" son sentidos como aquellos que le "cargan la mano a los demás". En el fondo, esta es una queja a la jefatura que debe poner órden y distribuir el trabajo de manera equitativa porque sino "terminan haciédole el trabajo a aquellos que por flojos no se lo merecen".

e. Comedor ("Se revolvió el olor a pescado con el desodorante ambiental")

El episodio del comedor se constituyó en el centro del conflicto de este momento, ya que el comedor generó un espacio en el cual se disolvió "la frontera" dentro de la oficina. Originalmente, el comedor pertenecía a una subsección. Pero al modernizarse permitió dar cabida a todos los funcionarios, en distintos horarios. Esto generó una lucha por el "microhondas" ya que hubo un subgrupo que vivió como una expropiación, el que pudiese ser utilizado por todos. A su vez el espacio del comedor tuvo que ser tácitamente reglamentado. ¿Qué se podia cocinar allí? ¿Qué se podía hacer? ¿Qué se podia decir, con qué intensidad se podian reír, qué tipos de chistes contar?. No fue facil llegar a acuerdos y los niveles de tensión fueron en aumento . Parecian dos bandos luchando por un territorio: uno llenando con "olor a pescado" y el otro invadiendo con "desodorante ambiental", mientras los compañeros comían.

En todo caso, el conflicto - que abarcó varias sesiones - se fue hablando y analizando hasta que se disolvió. Los mismos funcionarios reconocieron luego que se había llegado como a un acuerdo tácito , no sin violaciones a las normas (de horarios) implantadas.

Este momento permitió identificar la baja tolerancia que los funcioanrios tienen a las diferencias entre ellos (de rendimiento, de educación, de formas de ser y hasta de trabajo, para mencionar las más notorias) como si pretendieran que todos fuesen uniformizados al estilo de un batallón....

\section{4. Momento de los conflictos con el trabajo.}

Cuando los conflictos entre secciones y al interior de las secciones se fueron disipando comenzaron a surgir una serie de reflexiones sobre el trabajo mismo, sobre las tensiones que genera, sobre la relación que mantiene cada quién con su actividad. Este aspecto se convierte, en el sentir de los funcionarios, en un punto neurálgico ya que es poco lo que se puede hacer para cambiarlo por ser el motivo del empleo. Cuesta tomar medidas ante eso y en muchos casos se depende de instancias que están mucho más allá de la propia Oficina. Veamos algunos ejemplos:

a. Documentación personal y documentación oficial.

Perece ser que en un abuso de confianza - y también de autoridad - los funcionarios del Ministerio 
solicitan que la correspondencia personal de cuentas, cuotas, pagos, etc., les sea enviada al propio Ministerio, en lugar de a su domicilio particular. De este modo, el trabajo de la sección correspondencia se recarga excesivamente ya que una oficina prevista para la correspondencia oficial, debe trabajar el triple para cubrir también todas las cartas personales que llegan. Se quejan de la falta de ética al utilizar a los bienes estatales en beneficio personal.

b. Presión por terminar el trabajo en el día, y otras presiones por el estatuto administrativo.

El planteo se centra en lo que puede ser un trabajo contra reloj, o en su defecto, el tener que quedarse más allá del horario de salida para terminar con el trabajo del día. Si bien el estatuto lo establece de manera terminante, la cantidad de trabajo - sobre todo en determinadas fechas - puede ser desmesurado. Sorprende, en este caso, el exceso de celo por parte de los funcionarios, que no parece ser reconocido por parte de las autoridades.

c. El problema de la atención al público. La información que se obtiene es a través de relaciones personales y no oficiales. Ser la cara del Ministerio supone también sentir el peso de todo el Ministerio.

La sección de Información es de reciente creación y los funcionarios están muy orgullosos del trabajo que se ha hecho para organizarla y tratan por todos los medios de brindar un buen servicio. Sin embargo, notan que no reciben toda la información que requieren para canalizarla al público. Nadie les informa de nada y tienen que estar buscando la información para poder orientar al público consultante. Se siente la enorme responsabilidad de ser la cara del Ministerio, esto supone que son los que dan la cara pero también los que se encuentran en la primera linea de combate, lo que ocasiona..... no pocas tensiones y heridas. ("Somos la piedra de tope, los Colegios y los Directores hacen y deshacen y uno está en la mitad, el Ministerio no puede hacer nada, la gente descarga eso en noso- tros"). Y sobre todo cuando hay problemas que no se pueden resolver (ya que responden a politicas inciertas del propio Ministerio de Educación) y cuando no se cuenta con los datos mínimos para hacerlo de una manera eficiente. No les queda más que hacerse cargo de los problemas de las personas .... y sufrir las consecuencias - muchas veces enloquecedoras que el impacto del problema del público les produce. Con el teléfono no les va mejor. En suma, Información es "como la posta", pero allá los médicos y enfermeros se van endureciendo; acá eso no es posible.

Es evidente que no aparece claramente discriminado lo que es el brindar información al público de los reclamos que el público se cree con derecho de hacerle al Ministerio (padres y apoderados de diversas partes del país que muchas veces son "peloteados" desde las entidades locales, Municipios, unidades regionales, etc. ) y que realiza a través de la "cara del Ministerio", la oficina de Información.

\section{d. Trabajo rutinario ("Hacer lo mismo aburre y mata").}

Cuando el funcionario se ha pasado 25 años de su vida realizando el mismo tipo de trabajo mecánico, sin muchas posibilidades de creatividad, sin cambios y sin estimulo, comienza a gestarse una cierta sensación de desesperación. Se fantasea con la rotación de funciones; luego se concluye que no es viable, muchas actividades requieren una experiencia que no se adquiere de un día para otrro.

e. Descoordinación entre secciones (no se proveen de los materiales necesarios). "Todos se lavan las manos".

Si bien el objetivo de la burocracia es la racionalización del trabajo, en la práctica las cosas no funcionan de manera aceitada y muchas veces el trabajo de algunas secciones se ve detenido por el no cumplimiento de responsabilidades en fecha, por parte de otra sección. No parece ser un problema de no trabajo sino probablemente por la falta de comunicación entre las secciones que permita planificar las acciones con precisión y sobre todo 
cuando hay urgencias para cumplir diversas acciones al interior o al exterior del Ministerio.

f. La evaluación estadistica de todo. ("Todo se basa en la estadística, pero el drama está detrás.")

Los criterios de evaluación del rendimiento y de la calidad del trabajo del Ministerio, está basado en lo cuantitativo; lo cualitativo, las diferencias esenciales, no son para nada tomadas en cuenta. Este enfoque neoliberal de tener que medir todo afecta el funcionamiento de todo el Ministerio y de todas las acciones que el mismo emprende. "No hay calidad de vida en el trabajo, es para volverse loco". El sentido del trabajo y su evaluación aparecen distorsionados por la supuesta objetividad que los números aportan cuando lo único que se toma en cuenta son casualmente los números.

Para los funcionarios, que viven el trabajo como una totalidad, el Ministerio al tomar solamente la parte , los números, la estadística por el todo, distorsiona significativamente la realidad cotidiana, produciendo además un fenómeno ilusorio, que enajena a los funcionarios incrementando los niveles de sufrimiento laboral.

Este apecto es determinante para comprender la distorsión que se produce en la imagen del trabajo que se genera en los funcionarios, ya que el Ministerio se apropia (negándolo) de todo lo que hace a la relación entre trabajo-satisfacción-placerrealización personal, al valorar solamente las "cantidades" de trabajo. Se podría pensar entonces en un alto grado de enajenación producido estructuralmente por "el modelo " que cruza la acción del Ministerio.

g. Dificultad en aceptar los adelantos técnicos. ("Todo se va a computarizar. A uno le quitan el pensar.") Las innovaciones son siempre persecutorias ya que amenazan la estabilidad del empleo. Los funcionarios reaccionan, como es natural, defendiéndose de las máquinas y de la tecnologia, que inicialmente desplaza al trabajador. Es cierto que a la larga le soluciona muchos problemas, pero hasta conocer cual es el verdadero alcance de la tecnología , los funcionarios sienten temor. Pero además, queda claro que el Ministerio no tiene una politica de psicohigiene para introducir la nueva tecnologia, vale decir, generando procesos que disminuyan las ansiedades ante la nueva tecnología. La carencia de una politica explicita para disminuir las ansiedades ante lo nuevo, muestra la existencia de una política tácita que las aumenta. La capacitación técnica no alcanza a resolver las resistencias al cambio que la nueva tecnologia genera. Por otra parte, las fases de modernización necesarias lejos están de tomar en cuenta las opiniones de los funcionarios, por lo cual es común sentir entonces que los miembros de las diversas secciones no pueden pensar los problemas que les atañen: su capacidad de pensar no es tomada en cuenta por las autoridades.

\subsection{Conflictos con la institución (el Ministe- rio).}

Hay un momento en que el grupo de funcionarios toma conciencia de que los problemas que tiene con el trabajo dependen de las normativas, de la forma de organizar el trabajo, de la estructura burocrática, de las jerarquias, etc., que no necesariamente hace a la naturaleza del trabajo en sí, sino que pasa por la manera en cómo la institución norma la actividad laboral. Dicho de otro modo, los conflictos con el trabajo tienen un común denominador ya que hay responsables que toman decisiones sobre politicas y sobre formas de hacer las cosas a las que los funcionarios deben someterse.(4) No se trata entonces de un problema sobre la "naturaleza del trabajo en si “ (además, porque los fun-

(4)Loque se estácuestionandonoes lanecesidad deun ordenamiento sobre la actividad laboral yuna organización de la misma Loque se pone en entredicho es siesta manera de "hacer las cosas" (manejo despótico del poder, jerarquización arbitraria de funciones, invalidación de las iniciativas personales y grupales, control irracional del tiempo y del espacio, valoración de lo cuantitativo por sobre lo cualitativo, eficientismo, etc.) realmente es la mejor forma de hacerlas; cuánto esta normativa está realmente al servicio de los objetivos que el Ministerio dice perseguir. 
cionarios están plenamente convencidos de que el Ministerio y su trabajo, es muy importante, tal vez haciendo gala de mecanismos de idealización), sino sobre la manera en cómo se ejerce un determinado poder sobre el trabajo, y alli la violencia de la institución aparece en toda su magnitud.

En lo concreto, se vuelven a explicitar en el grupo muchos de los planteos que se hicieron sobre la figura del Jefe, ya que éste encarna en el espacio de la Oficina a la institución. Sin embargo, en esta oportunidad hay una mayor discriminación, en el sentido de que el Jefe es también un engranaje del Ministerio y de que los problemas rebasan su esfera de responsabilidades.

a. El estatuto administrativo no respeta las necesidades de las personas.

La violencia que el estatuto administrativo rígido instaura, solamente puede ser combatido violando a su vez su letra. Veamos algunos ejemplos:

- Si la rutina los agobia y el encierro los abruma, deben entonces tomarse más del tiempo estipulado para la colación para tener un momento de desahogo.

- Si hay problemas en el hogar, cuidado de los hijos o de familiares y deben hacerlo, no hay otra forma más que recurrir a las licencias mentirosas.

- Si el horario de llegada es muy estricto y aparecen descuentos por llegar un minuto tarde ("me ponen un 6 si llego atrasada"), hay que recurrir a otros mecanismos fraudulentos para contrarrestar los descuentos ("La carrera del minuto", que no ha dejado de provocar accidentes por correr).

En todo caso, estas acciones no dejan de generar culpa, lo que afectará el trabajo, ya que es como si el propio Ministerio no les permitirá ser honestos al inducirlos a prácticas corruptuas.

b. Los salarios son ampliamente insuficientes e inequitativos. Sienten que la situación general es caótica; colaboran con algunos funcionarios para juntar papeles sobrantes de las oficinas para venderlos y mejorar el salario, otros venden huevos, miel, etc. Sienten que los niveles de bienestar antes de la dictadura eran muy superiores: tenían médico, dentista, jardin de niños, comedor y posibilidades de comprar las mecaderías básicas. El salario en esa época tenía un mayor poder adquisitivo ("Les quedaba dinero para el otro mes"). El estatuto administrativo incide desfavorablemente ya que las calificaciones generan una "baja del salario" y una dificultad para ascender en el escalafón. En este rubro la impotencia es absoluta ya que sienten que "El Ministerio no tiene remedio", que no pueden hacer nada para mejorar la situación ya que todo está amarrado, deben soportar con rabia e indignación. La angustia aumenta ante la posibilidad de jubilarse ya que lo acumulado no les alcanzará para siquiera sobrevivir dignamente. A pesar de eso " deben dar gracias a Dios de tener un trabajo".

La impotencia y la rabia señalada en este punto cruzó de manera transversal todo el desarrollo del grupo durante todo el taller, manifestándose de diversas manera según el momento pero estando permanentemente presente.

c. Niveles de corrupción en el trabajo.

El grupo observa que se da un pago de horas extraordinarias a funcionarios por misiones que no son realizadas. Existen además, contrataciones que se saltan niveles del escalafón y con sueldos muy por encima de lo que estiman que corresponderia.

d. Falta seguridad en el trabajo.

Este aspecto apunta a mostrar diversos niveles: Muchos funcionarios renunciaron a su base por obtener un mayor salario en el sistema de contrata, el cual no da garantias laborales de permanencia y ante las situaciones de crisis social y económica, aparece el fantasma del despido. Este aspecto se agrava cuando los funcionarios tienen ya muchos años de trabajo, no tiene los grados para obtener un buen salario y no pueden ni siquiera decidir irse del Ministerio. 
- En otro sentido, la seguridad tiene que ver con cosas mas concretas, como los accidentes en el trabajo, a la entrada o en las escaleras, falta de escaleras de incendio, sobre todo en un país en el cual los terremotos son una preocupación permamente ("Las grietas del edificio terremoteado están cubiertas con pura pintura”), etc.

e. El peso de la dictaduray su relación con la institución.

El grupo siente como una fractura en su historia el acontecmiento del golpe militar y la consolidación de la dictadura que implicó una honda distorsión en las relaciones laborales y en el clima de trabajo. Funcionarios que fueron perseguidos y detenidos, clima de persecusión permanente, prohibición de conversar de a dos, sumarios, aplicación brutal de las normativas, la planta fue drásticamente disminuída, etc.

Cuando se perdió una carta, la Oficina fue sumariada por parte de la Fiscalia Militar, se les exigó a algunos funcionarios que "se echaran la culpa". En suma, la experiencia de la dictadura significó una marca permanente de miedo que aún subsiste en muchos. Herida, que como en muchos otros sectores de la sociedad chilena, ha permanecido abierta generando autocensura y sufrimiento.

\section{f. Las enfermedades que el trabajo genera. "Si- tuación sin salida".}

Los problemas que no se pueden resolver, generan un monto de angustia importante, les echa a perder la vida, se deprimen, se enferman por la rabia de no poder decir las cosas durante tantos años. Cosas que no se pueden remediar y se repiten. La rabia que no se puede canalizar hacia afuera termina apuntando a la propia personalidad en diversas manifestaciones de autoagresividad y desvalorización.

Este aspecto da cuenta del daño que se ocasiona en el personal cuando no hay politicas de psicohigiene en el trabajo. ¿Qué hacer con las tensiones que se generan? ¿De qué manera las mismas pueden ser descargadas y elaboradas? Si no existen estos mecanismos de procesamiento, su acumulación paulatina irá minando progresivamente el cuerpo de los funcionarios a través del proceso de somatización de las tensiones.

("Somos corderos", "no puedo", "no quiero", "no me siento capaz"," no hay solución", "no puedo discutir", "es como echarle agua a un canasto", "no se puede hacer nada", etc.). La resultante es la variedad de enfermedades psicosomáticas que los funcionarios presentan, muchas de las cuales van acompañadas de diversos estados depresivos más o menos cíclicos o en otros casos el alcoholismo crónico.

\subsection{El momentodelos problemas con el sindi- cato.}

La única respuesta posible para enfrentar a la institución, que aparece como poderosa y sólida, es la unión de los funcionarios a través de una organización que les de posibilidades de luchar. Por tanto, cuando los funcionarios se plantean algún tipo de proyecto reivindicativo, algún tipo de acción de conjunto para mejorar sus condiciones laborales, surge inmediatamente el tema del sindicato que acapara las tensiones y que marcan la presencia del conflcto central. Pero el sindicato tambián abre a un sinnúmero de dificultades entre ellos y con la organización que dice representarlos:

a. Distancia entre los representantes y la base.

Uno de los primeros problemas que surge es que los representantes no informan a la basa acerca de los proyectos y actividades que se realizan y cuando los funcionarios se atreven a preguntar reciben dilatorias

- Acusan a la dirigencia de acordar con el Ministerio a espaldas de sus necesidades. Existe falta de organización al interior del sindicato que estimule la participación y mantenga a todos en sus lugares.

- Al no saber "en qué andan" los dirigentes, tienen dudas sobre sus realizaciones y compro- 
miso con la base. Por otra parte, los dirigentes "la pasan muy bien, en reuniones y comidas" y gozan además de las licencias sindicales, lo cual visualizan como un beneficio singular.

b. Politica solamente economicista cuando pesan otros problemas.

El Sindicato solamente se preocupa de cuestiones del salario cuando habria un amplio abanico de problemas que deben ser tratados en la mesa de las negociaciones, vinculados a los beneficios que se tuvieron y que se perdieron cuando la dictadura.

Reconocen asimismo, que su participación en el sindicato es esporádica, no asisten a las reuniones de manera regular y están bastante divididos al interior del mismo, lo que no deja de quitarle a la organización posibilidades operativas.

En el fondo no ven que el sindicato represente una herramienta que tenga funciones especificas de representación y de defensa de los funcionarios, no es sentido como algo propio, del cual pueden disponer para asesorarse de manera permanente.

\subsection{El momento de la articulación delos pro- blemas familiares con el funcionamiento institu- cional.}

Finalmente, el grupo vuelve a plantear inquietudes acerca de la vida personal, ahora centrados en la vida familiar y sus conflictos. Sin embargo, en la medida que avanza el análisis se comienzan a descubrir relaciones de funcionamiento similar entre esa vida familiar personal y la manera en cómo los conflictos laborales son vividos. Dicho de otro modo, los modelos de comunicación, las demandas hacia compañeros y jefes, las actitudes, las reacciones caracterológicas, en fin, es como si el modelo de funcionamiento familiar fuese transpuesto al ámbito laboral.

Lo grave de la situación es que dicha transposición genera no pocas pasiones en los encuentros laborales, perdiéndose buena parte de la distancia necesaria que la situación formal del trabajo reque- riria. Ello ocasiona que en la subjetividad, los funcionarios vivan pendientes en el ámbito laboral de las situaciones familiares que cada uno vive, ya que translada y actualizan con los compañeros todos esos conflictos. Asi, hay una pérdida de distancia evidente y cada encuentro es polarizado en una situación de amor-odio (como en la familia, los afectos están primero) lo cual trasciende con creces una relación más formal y eficiente como debiera ser la situación del trabajo: privilegiar el pensar ( trabajo) sobre el sentir (familia).

¿Por qué se produce este fenómeno? Escuchemos al grupo: "Pasados los 40 todos son cambios malos, no hay calidad de vida, vivimos lejos, se ve sólo lo trágico, temor a los asaltos, todo el día tensa, aburrida, somos personas llenas de temores, vivir endeudado “. Es decir, el grupo tiende a enquistarse en la vida familiar, aislándose del medio que sienten como agresivo, y como el empleo insume más tiempo que la vida familiar, alli se vive la familia.

El medio social, cada vez más agresivo, gatilla la implementación de mecanismos de aislamiento y de búsqueda de lugares más seguros para protegerse de una sociedad que produce temor. El refugio natural es el medio familiar, que es el espacio conocido y tradicional de protección. Pero el caso es de que los funcionarios pasan de 8 a 9 horas juntos, por lo que el campo del trabajo se convierte en el lugar de protección, desplazando alli todas las características protectoras del grupo familiar de origen.

"Se arman las peleas como italianos". "Esto es una familia, pasamos todo el dia juntos", "tenemos mamáy madrastra", "nos echamos de menos." "Los problemas se solucionan dentro de la familia"," los trapos sucios se lavan adentro". "Hay solterones amargados", "soledad entre nosotros", "nos damos un gusto y al otro día ni para la micro". Las deslealtades son entendidas como familiares y no en relación al problema del rendimiento que el trabajo implica. "El abuelo sería el Ministro". "Acá hay problemas de comunicación como en la familia". Reflexionando sobre los lios que tuvieron por el comedor, afirman "acá, las discusiones son en la mesa, los italianos respetan la mesa”. 
También aparecen los problemas entre generaciones: "hay una generación que entra joven, ellos no se hacen problemas". Esta referencia obviamente también alude a la estructura familiar y a los grados de responsabilidad que cada quién asume en su interior.

\section{Alcances del Proceso. los CambiosProducidos.}

Comprender el proceso como el desarrollo de un conflicto que va cambiando de cara, permite también evaluar los alcances del mismo y determinar los cambios que el proceso produjo.

El esclarecimiento se produce cuando el grupo a partir del acto de poner en palabras, simboliza situaciones, atribuye sentidos y produce a su vez nuevos sentidos. Esto permite transformar una experiencia impactante, inasible, "traumatizante", en un acontecimiento que al insertarse en una lógica, adquiere significaciones diversas. Por tanto, si bien el conflicto cambia de cara, las situaciones continúan permaneciendo, no hay olvido o represión posible, hay simplemente re-significación. Pero ello es suficiente para que el conflicto pierda buena parte de la intensidad que es vivida como "traumática". Por tanto, el análisis progresivo de las situaciones en el decir de los funcionarios - hace que el conflicto que en un momento fue sentido como antagónico, más tarde ha perdido buena parte de su intensidad.

$\mathrm{El}$ "espacio para hablar" adquiere para aquellos que se animan a aprovecharlo, el sentido de una particular descarga emocional que no es otra cosa que ese re-ordenamiento de las escenas más ansiógenas. El grupo oficia como continente de las mismas y como un espacio de solidaridad donde el compromiso colectivo permite pequeñas modificaciones, muchas veces suficientes para disminuir el sufrimiento personal.
Los cambios (que no se agotan en lo registrado al finalizar la intervención) (5) están limitados por cuestiones de la conformación de la realidad en la cual los sujetos construyen su vida cotidiana. Por ejemplo, no pueden operando individualmente, modificar sus sueldos y beneficios, pero si pueden - individual y colectivamente - asumir una relación con el trabajo y entre ellos más creativa, que resulte menos mecánica y frustrante. Pueden, autogestionar amplios espacios de su trabajo y utilizar su ingenio para descubrir las fisuras de la institución y combatir así, algunas de sus arbitrariedades.

\section{Sobrelaevaluación}

Se realizó en dos momentos: el primero consistió en presentar a los funcionarios un cuestionario para evaluar el proceso.Esta forma se vió enfrentada con el estereotipo que tienen los funcionarios públicos que están habituados a evaluar personas. Así, el tema de la evaluación no dejó de ser persecutorio lo que ocasionó que varios de ellos buscaran conciente o inconscientemente formas de "escabullirse". Esto mostró una vez más, la rigidez implantada por la institución en la materia, reactivándose las fantasias sobre las evaluaciones personales (calificaciones) y la incidencia de la misma en los criterios institucionales sobre "asistencia", "colaboración", etc. En suma, el fantasma presente era aquel de si el el funcionario es o no "conflictivo".

Por tanto, esta metodología de evaluar resultó no solamente novedosa sino también desestructurante.

El segundo momento consistió en abrir la evaluación a una discusión colectiva. Alli fue posible cotejar impresiones y deslindar algunos "logros", así como la permanencia de patrones enfermantes y estresantes de gran arraigo. 
Es de destacar que algunos funcionarios sufrieron de depresión a partir de la visualización de la finalización del taller. A nuestro juicio ello muestra que el taller además tuvo para algunos un espacio privilegiado de estabilidad personal, ya que el mismo les permitia poner en palabras y elaborar, en un clima de escucha, muchas de las ansiedades que la vida cotidiana y el espacio laboral genera, mostrando a su vez la necesidad de ese tipo de espacios de manera permanente.

Otros funcionarios, no quisieron acercarse. En total participaron del proceso evaluatorio la mitad de los funcionarios que comenzaron el taller, porcentaje levemente menor que aquel que asisitió la mayoria del tiempo.

Los funcionarios, en el proceso de evaluación del taller reconocen:

a. Mejoria en las relaciones humanas: reconocen que están menos sensibles a los vinculos entre ellos lo cual ocasiona que no se ofendan tanto entre si.

Las discusiones y análisis realizados en el taller permitieron limar asperezas, lo cual supone que hay conflictos interpersonales que se han disuelto.

Además, el conocer más acerca de las situaciones personales de los diversos compañeros, facilitó en el grupo una mejor comunicación, comprensión y respeto, por lo cual los limites interpersonales se vieron modificados.

b. Efecto catártico: El espacio del taller sirvió para desahogar situaciones antiguas enquistadas y tensas, lo cual produjo una significativa relajación de la tensión entre los funcionarios, más marcado entre algunos de ellos.

c. Toma de conciencia de su realidad laboral: El análisis pormenorizado de su situación laboral, esclareció al grupo sobre muchos factores que operan diariamente en el ámbito laboraly acerca de los cuales no tenian clara conciencia. Ello implicó mejorar los niveles de discriminación entre aquellos problemas que pueden ser abordados de manera individual y grupalmente, de otros que al ser estructurales requieren de movimientos institucionales mucho más amplios. La toma de conciencia sobre la situación laboral implica a su vez un reconocimientos tanto de las potencialidades como de las limitaciones personales. Estos reconocimientos no se dieron de manera gratuita, por el contrario causaron no poco dolor y sufrimiento de manera transitoria.

d. Reconocimiento de la función de un "espacio para hablar". La vida cotidiana en el ámbito laboral es generadora de rutinas que al formalizarse incomunican a las subjetividades en juego. El "espacio para hablar" generó un "lugar de la verdad", en el sentido de que ellos podian decir lo que sentian, comunicarse con los otros y descubrirse en aspectos desconocidos para ellos mismos. Esto asustó a algunos - el poder de la verdad de las palabras - y en otros casos fue sentido como deslealtad. Sorprende que funcionarios que hace 35 años que están trabajando en el mismo puesto y rodeados de las mismas personas, desconozcan aspectos de los demás esenciales para la conviviencia. "Las cosas se repiten pero ahora se ven con otros ojos."

A su vez, además de lo señalado por los funcionarios, desde el lugar del especialista , podemos decir que en muchos casos, el individualismo de los funcionarios, les impide tomar conciencia acerca de sus posibilidades como grupo, sus potencialidades de creatividad para sortear lo que sienten como "cuellos de botella" y disponer de sus recursos psiquicos para dar solución a algunos problemas cotidianos. En muchos casos, se autoculpan de los problemas burocráticos que les atañen, mostrando su dificultad para tomar distancia de los mismos y comprender las determinaciones estructurales.

Hay que comprender que para el funcionario, solucionar los problemas que se le presenta es la única forma de satisfacción que recibe de su trabajo; por tanto, es cuando el trabajo adquiere sentido. Por ello, el funcionario no puede dejar de buscar 
sentirse satisfecho cuando hay un trabajo bien realizado que se completa, que se concluye. Esto hace que el funcionario asuma responsabilidades que están mucho más allá de sus compromisos laborales y que tienda, por todos los medios, a darle feliz solución. La institución sabe eso y de algún modo juega deslealmente con dicha alternativa: el funcionario siempre va a hacer más que para aquello que ha sido contratado.

Los funcionarios, entonces, se hacen cargo de problemas institucionales - exhibiendo una extrema omnipotencia - que, a ojos vista, corresponden a otras instancias de resolución, según la estructurajerárquica del Ministerio. Este tipo de problemas mayoritariamente no podrán ser solucionados, produciendo en el personal angustia y frustración.

Esto genera que inicialmente el funcionario se culpe cuando algo sale mal o cuando no puede solucionar un problema, independientemente de que en muchos casos, la solución del mismo no pertenezca a la esfera de sus compromisos laborales.

Debe entenderse además, que la búsqueda de soluciones para estas situaciones, se realiza de manera individual; por ello, hay una acumulación progresiva de tensiones que va minando la salud de las personas. Es solamente en el espacio interpersonal que los funcionarios pueden darse cuenta de que las raíces de los problemas están más allá de sus posibilidades, generándose entonces la vía de la descarga y de la elaboración. Correspondería investigar acerca de los motivos que determinan que la via colectiva aparezca con tanta dificultad para ser encontrada.

\section{Sugerenciasa Futuro}

Del análisis del proceso se pueden realizar algunas apreciaciones con proyección a futuro.

\section{Espacios para hablar:}

Sería conveniente estudiar la posibilidad de generar de manera periódica (cada 15 días) una suerte de espacio en el cual los funcionarios, al margen de jefaturas, pudieran acceder voluntariamente a un espacio en el cual puedan compartir sus inquietudes y angustias cotidianas.

\section{En loadministrativo:}

a Capacitación: Si bien el Ministerio tiene una muy buena disposición para capacitar permanentemente a sus funcionarios, pareciera ser según los funcionarios - que en muchos casos estos cursos no necesariamente responden a una programación que detecte prioridades de necesidades de los funcionarios. Además, no pareciera existir una politica de evaluación y seguimiento de los programas de capacitación, que tenga repercusiones a su vez, en el estatuto salarial y escalafonario del funcionario.

b. Rotación : si bien este es un aspecto complejoy frente al cual los funcionarios tienen diversos grados de resistencia (tal vez por temor a perder "su feudo") podría convenir estudiar en conjunto con los afectados, bajo qué parámetros y en qué funciones la rotación es posible.

c. Desnormativización del trabajo: El trabajo que los funcionarios realizan está tan estrictamente normado que es imposible realizar cambios creativos para que el mismo resulte más gratificante. El Ministerio no aprovecha ni la capacidad ni la sabiduría de los propios funcionarios para ir dando nuevas soluciones a viejos problemas, generando mayores niveles de participación y compromiso . Es una manera de manifestar confianzay estímulo de la institución hacia sus funcionarios.

d. Calificación: El sistema resulta ser persecutorio y arbitrario lo cual más que apoyar el desempeño de la gestión ocasiona casualmente lo contrario: incrementa de manera significativa los niveles de miedo y de estrés. Es un elemento eminentemente represivo que afecta la situación salarial y la seguridad futura (jubilación).

Ya que el sistema de calificación afecta la totalidad del Ministerio, debiera cuestionarse los efectos que está produciendo, los que resultan antagónicos con los objetivos para los cuales fue propuesto. 


\section{Políticadeselección:}

"El Ministerio tiene la politica de reventar al funcionario, la instritución mata".

Tanto la Organización Mundial de la Salud como la Organización Internacional del Trabajo recomiendan realizar cada vez más, un análisis de las condiciones del empleo y de las características de personalidad de los aspirantes. Se ha visto que hay tipos de empleos que desencadenan la psicopatología personal y familiar en algunos tipos de personalidad, mientras que otros empleos los ayudan a mantener la salud mental.

Dicho de otro modo, se trata de ubicar a cada funcionario en el lugar más adecuado para preservar su higiene mental en lugar de sabotear con el trabajo su estructura de personalidad. Esta politica redunda en beneficio tanto del trabajador como del trabajo. Sería una de las maneras de comenzar a combatir el alto indice de enfermedades psíquicas y psicosomáticas que se observan en la Oficina.

Conviene precisar que si bien esta Oficina de partes presenta una situación particularmente preocupante para el Ministerio, lo que motivó la realización del Taller, sus características generales no se diferencian de lo que constituye un perfil de los problemas que se encuentran en otras reparticiones, estatales y privadas. Por tanto, es preciso interrogarse acerca de las características del modelo de trabajo que el régimen implanta y que ocasiona este tipo de sufrimiento y excesos. En tal sentido, las estadísticas nacionales sobre depresión y causas de mortalidad, reflejan situaciones que dan cuenta de un mal manejo de la agresividad, autoagresividad, violencia e impotencia. El problema de esta Oficina develado a través de este Taller, muestra de manera dramática estas sobredeterminaciones.

\section{Bibliografia}

Anzieu, Didier y otros 1978: El trabajo psicoanalitico en los grupos, S. XXI, México.

Anzieu, Didier 1986: El grupo y el inconsciente, Bib. nueva, Madrid.

Baremblitt, Gregorio y otros 1991: El espacio institucional No 1 , Lugar Editorial, B.A..

Baz, Margarita 1996: Intervención grupal e investigaciōn, UAMX, México D.F..

Bauleo, Armandoy otros1983: La propuesta grupal, Folios, México.

Bauleo, Armando y otros 1990: La concepción operativa de grupo, Asoc. española de neuropsiquiatria, Madrid.

Castoriadis, Cornelius 1983: La institución imaginaria de la sociedad, Vol. 1 y 2, Tusquets, Barcelona,

Fernández, Ana Maríay DeBrasi, J uan Carlos 1993: Tiempo histórico y campo grupal, Nueva Visión, B.A..

Foladori, Horacio 1992: Del deseo a la autogestión, TRAMAS, UAM-X, México.

Foladori, Horacio1993: El grupo análisis: técnica de diagnóstico de clima organizacional, Revista PSICOLOGIA,Vol. IV, U. de Chile, Santiago.

Foladori, Horacio 1994: La salud de la institución, HIGIA, Año 2, $\mathrm{N}^{0}$ 3, Santiago.

Foladori, Horacio eHidalgo, Ricardo 1998: Intervención en un Hospital geriätrico, Revista PSICOLOGIA, Vol. VII, U. de Chile, Santiago.

Foucault, Michel 1979: Enfermedad mental y personalidad, Paidos, B.A.,

Guattari, Felix 1976: Psicoanálisis y transversalidad, S. XXI, B.A. Guattari, Felix y otros 1981: La intervención institucional, Folios, México.

J aidar, Isabel y otros 1998: Tras las huellas de la subjetividad, UAM-X, México, D.F.

J asiner, Graciela y Woronowski, Mario 1992: Para pensar a Pichón, Lugar Ed., B.A.

Kaës, Renéy otros 1982: Le travail psychanalytique dans les groupes,Dunod, París,

Kaës, Renéy otros 1989: Lainstitución y las instituciones, Paidos, B.A.

Kaës, René1995: El grupo y el sujeto del grupo, Amorrortu, B.A. Kononovich, Bemardoy Saidon, Osvaldo 1991: La escena institucional, Lugar Editorial, B.A.

Kononovich, Bernardoy Saidón, Osvaldo 1994: El cuerpo en la clinica institucional, Lugar Ed., B.a.

Lapassade, Georgey otros 1977: El análisis institucional, Campo abierto, Madrid,

Lourau, René1975: El análisis institucional, Amorrortu, B.A. Lourau, René1980: El Estado y el inconsciente, Kairos, Barcelona. Mendel, Gérard 1974: Sociopsicoanálisis No 1 y 2, Amorrortu, B.A. Mendel, Gérard 1993: La sociedad no es una familia, Paidos, B.A. Pichón-Rivière, Enrique1975: El proceso grupal, Nueva Visión, B.A. 